\title{
What Not to Make of Recalcitrant Emotions
}

\author{
Raamy Majeed \\ University of Auckland \\ Erkenntnis (forthcoming)
}

\begin{abstract}
Recalcitrant emotions are emotions that conflict with your evaluative judgements, e.g. fearing flying despite judging it to be safe. Drawing on the work of Greenspan (1988) and Helm (2001), Brady (2009) argues these emotions raise a challenge for a theory of emotion: for any such theory to be adequate, it must be capable of explaining the sense in which subjects that have them are being irrational. This paper aims to raise scepticism with this endeavour of using the irrationality shrouding recalcitrant episodes to inform a theory of emotion. I explain (i) how 'recalcitrant emotions' pick out at least two phenomena, which come apart, and (ii) that there are different epistemic norms relevant to assessing whether, and if so how, subjects undergoing recalcitrant bouts are being irrational. I argue these factors result in differing accounts of the precise way these emotions make their bearers irrational, which in turn frustrates present efforts to adjudicate whether a given theory of emotion successfully meets this challenge. I end by briefly exploring two possible ways a philosophy of emotion might proceed in the face of such scepticism.
\end{abstract}

KEYWORDS: recalcitrant emotions; irrational emotions; rationality; epistemic norms

Recalcitrant emotions, according to D'Arms and Jacobson, are emotions that exist "despite the agent's making a judgment that is in tension with it" (2003: 129). For example, you fear Fido, your neighbour's dog, which you judge to be harmless. The phenomenon of emotional recalcitrance is said to raise a challenge for a theory of emotion. Drawing on the work of Greenspan (1988) and Helm (2001), Brady argues that this is "to explain the sense in which recalcitrant emotions involve rational conflict or tension” (2009: 413).

Meeting this challenge is regarded as being crucial for emotion research. This is because it is used as a condition of adequacy for a theory of emotion. Brady, for instance, argues as follows: 
For we have an intuitive sense that there is something wrong, from the standpoint of rationality, when fear persists in the face of a subject's judgement that she is in little or no danger. In such a situation, we think that the subject should either stop being afraid, or should change her evaluative judgement. If she does not, then it seems as though the subject is violating some normative principle governing the relation between emotions and evaluations. A condition of adequacy on a theory of emotion is that it should be capable of capturing such normative principles, and thus capable of explaining just why it is that emotions are irrational when they violate such principles. (Brady 2009: 414)

The point here about norm violations is nuanced. The claim isn't that our theory of emotion should be as such that recalcitrant emotions don't turn out to violate such norms. Rather, it is that recalcitrant emotions do appear to violate them, and any theory of emotion worth its salt should be able to account for the intuition that subjects undergoing recalcitrant emotions are irrational on account of these emotions violating such norms. This paper aims to raise some problems with this way of understanding the nature of emotions.

In what follows, I argue these problems result from the phenomenon being under-described $(\S \mathrm{I})$, and there being different epistemic norms that are violated by recalcitrant episodes (§II). Both of these factors result in differing accounts of the precise way recalcitrant emotions make their bearers irrational, which in turn frustrates any effort to adjudicate whether a given theory of emotion adequately meets the challenge such emotions pose, viz. whether it can account for the way recalcitrant emotions make those who undergo them irrational. Note: I don't think these problems are insurmountable. But they are pressing. The second problem, in particular, won't be resolved until we have settled the controversy over which epistemological framework we ought to adopt towards the emotions more generally. The lesson, then, though modest, I think is an important one: as things stand, it is ill-advised to employ the intuition that subjects undergoing recalcitrant emotions are be- 
ing irrational to inform a theory of emotion. I end by briefly exploring two possible ways a philosophy of emotion might proceed in the face of this lesson (§III).

\section{I.}

Recalcitrant emotions were originally employed as a way of objecting to judgementalism: the view that judgements are either constitute of, or at least necessary for, emotions. ${ }^{1}$ In brief, if having an emotion requires the relevant judgement, the subject undergoing a recalcitrant emotion must be making contradictory judgements. For example, if subject $S$ can only fear an object $x$ if she judges that $x$ is dangerous, then when $S$ undergoes a recalcitrant bout of fear, she simultaneously judges that $x$ is dangerous and that it is not. The charge against judgementalism here is that it ends up attributing a radical, and therefore implausible, form of irrationality to subjects undergoing emotional recalcitrance. This in itself isn't a knockdown argument against judgementalism. But critics, e.g. Greenspan (1981, 1988), argue given the choice between allowing for the existence of emotional episodes that aren't grounded in judgements, and judgemental inconsistency which results from denying their existence, we should opt for the former. ${ }^{2}$

Whether judgementalism can adequately meet this objection is orthogonal to the concerns of this paper. ${ }^{3}$ But the objection helps us do two things. First, it helps introduce an all important caveat. The phenomenon of emotional recalcitrance was first introduced not as a way of challenging theories of emotions more generally, but to challenge a particular theory of emotion, namely judgementalism. It is my view that the phenomenon is telling against judgementalism; there is a vio-

${ }^{1}$ Proponents of the view include Solomon (1980) and Nussbaum (2001).

2 Also see Deonna and Teroni (2012: §5) and Benbaji (2013).

3 A judgementalist might be able to explain emotional recalcitrance without positing contradicting judgements, e.g. a subject judges that flying is safe but still feels fear because what he actually fears is not flying itself, but the prospect of flying. This point due to Solomon, is mentioned, though not examined, by D'Arms and Jacobson (pg. 129, fn.6). Also see Grzankowski (2016), who explains how judgementalists can deny attributions of radical irrationality by claiming that subjects endorse conflicting contents under different concepts or different modes of presentation. 
lation of an epistemic norm when subjects make contradictory judgements, and it is best that a theory of emotion make do without it. My worry is with the use of the phenomenon to inform a theory of emotion more generally. In other words, the worry is with the contemporary challenge of emotional recalcitrance, where it is a requirement of any adequate theory of emotion that it explain the sense in which such emotional episodes involve rational conflict. As I hope to make clear, an explanation of rational conflict gets a lot trickier when we move away from the judgementalist scenario where bouts of emotional recalcitrance, in effect, involve the subject making two contradictory judgements.

Second, the objection helps highlight my first concern with the employment of recalcitrant emotions to drive a theory of emotion more generally, viz. the phenomenon is under-described. The overwhelming majority of discussions of emotional recalcitrance assume a pre-theoretical familiarity with the phenomenon. ${ }^{4}$ Moreover, expositions of the phenomenon typically don't extend beyond the conflict definition, e.g. by D'Arms and Jacobson, and a few terse examples, e.g. "Jonas believes firmly that the spider is not dangerous, yet he is terribly frightened. Mary is convinced that she has done nothing wrong, yet she is assailed with crushing guilt" (Deonna and Teroni 2012: 54). This is understandable given that such minimal descriptions suffice for an exposition of Greenspan's charge against judgementalism. The worry is they mightn't if we are to employ such emotional episodes, especially how they violate epistemic norms, to drive a theory of emotion more generally. Ironically, Greenspan herself proves to be an exception, and provides several detailed examples. The problem, however, is she discusses two phenomena which, though related, come apart: groundless emotions and emotions that conflict with our judgements. ${ }^{5}$

Groundless emotions for Greenspan aren't emotions that are groundless in any sense whatsoever, but "emotions not grounded in evaluative judgements of their objects" (1981: 165). This is

\footnotetext{
${ }^{4}$ E.g. D'Arms and Jacobson describe it as a "familiar psychological phenomenon" (2003: 129).

5 There are other exceptions, e.g. Rorty (1978) provides in-depth examples when discussing emotional akrasia, and Dillon (1997) does likewise in her analysis of self-respect. These examples also run-together groundless emotions with emotions that involve conflict.
} 
why she sometimes speaks of them as emotions "radically dissociated" from our judgements. There is good empirical evidence to suggest that emotions can be thus dissociated. For instance, the twinpathway model of emotion generation, which LeDoux (1996) confirms is implemented at the neural level, shows how emotions can be generated in two ways: roughly, via (1) a thalamus-to-amygdala circuit, which bypasses the cortex, is 'quick and dirty', and occurs without the conscious experience of the stimulus, and (2) a thalamus-to-cortex-to-amygdala circuit, which is slow, and occurs with the conscious experience of the stimulus. Groundless emotions can be accounted for given the existence of circuit (1). ${ }^{6}$

A clarification. The empirical data considered here might, in actual fact, support a more radical form of groundless emotion, one which would prove an addition to the kinds of phenomena classified as recalcitrant emotions. Groundless emotions, as Greenspan considers them, are emotions that aren't grounded in evaluative judgements of their objects. But if the data proves correct, it might be that emotions can lack what Deonna and Teroni call "cognitive bases": 7

Perception gives us direct access to the relevant objects and facts in the sense that it does not call for the presence of another mental state directed at these very objects and facts, where's emotions must latch on to information provided by other mental states. And these mental states, which we shall call cognitive bases of emotion, can be of radically different types" (Deonna and Teroni 2012: 5)

The cognitive base of an emotion, then, is whatever type of mental state which acts as their basis. For example, they note that emotions directed at the past might have memories as their basis, whereas those directed at the present are typically based on perception, and those about the future can be based on imaginative expectations. Do the existence quick and dirty emotion-generating sys-

\footnotetext{
6 This model of emotion generation should give judgementalists cause for concern, but they could respond that emotional responses generated via circuit (i) won't legitimately count as emotions because they lack the relevant evaluative judgements which help individuate them from similar responses.
}

7 I am grateful to an anonymous referee for this suggestion. 
tems actually suggest that emotions can lack cognitive bases? The answer, at least in part, will depend on what we mean by perception. Circuit (1) generates emotional responses without the conscious experience of the stimulus. Nevertheless, whether this entails that there is no perception of the stimulus is a point of contention. Blind-sight cases suggest that we can have unconscious perceptions, as cortically blind subjects can respond to visual stimuli significantly well above chance despite reporting to not be able to consciously see the stimuli. ${ }^{8}$ If such cases are really telling of unconscious perception, then the quick and dirty path to emotion-generation needn't entail that such emotions lack cognitive bases. They plausibly have unconscious perceptions as their cognitive basis.

A proper investigation into the implications of circuit (1) vis-a-vis emotions without cognitive bases will take us too far afield. What is directly relevant to our concerns here is that emotions generated via this circuit need not give rise to any conflict. This is precisely why Griffiths's $(1990,1997)$ explanation for what he calls "irrational emotions" doesn't fully account for the contemporary problem of emotional recalcitrance, which involves conflict. Drawing on the work of LeDoux, Griffiths argues that emotions can sometimes be triggered without the cognitive process of belief-fixation that gives rise to judgement. For example, "If, however, only the affect-program system [roughly, circuit (1)] classes the stimulus as a danger, the subject will exhibit the symptoms of fear, but will deny making the judgements which folk theory supposes to be implicit in the emotion" (1990: 191). This explains how emotions can be radically dissociated from judgement, but it doesn't directly speak to any conflict between emotion and judgement.

It is my view that we can, in addition, employ the twin-pathway model to account for how there can be such a conflict. Roughly, such conflict arises when the thalamus-to-amygdala circuit generates an emotion (sans an evaluative judgement), which happens to conflict with a judgement the subject already holds. ${ }^{9}$ For instance, a subject may hold the prior belief that she is unafraid of

\footnotetext{
8 See Weiskrantz (1986) for an overview.

9 This provides a causal explanation of the conflict, but it doesn't resolve one of the key controversies shrouding emotional recalcitrance, viz. the precise nature of this conflict.
} 
snakes, and still have her fear responses elicited when presented with a snake. If these responses are elicited via circuit (1), her response will be rapid; much too rapid for her to have a conscious experience of the stimulus, and thereby make any judgements about what it is, let alone whether it is dangerous. In this instance, we would have a groundless emotion, which also conflicts with an evaluative judgement. Nevertheless, the fact that emotions can be thus generated in the absence of any preheld judgements that conflict with them also illustrates how emotions can be groundless without involving any conflict.

Similarly, emotions can involve conflict without being groundless. Of course, if judgementalism is true, all emotional episodes, whether they involve conflict or not, will be grounded in judgement. But we needn't be judgementalists to suppose that some emotional episodes can simultaneously be grounded and involve conflict. To clarify, what makes judgementalism implausible isn't that it makes subjects undergoing certain bouts of emotional recalcitrance too irrational, but that it makes any, and all, cases of emotional recalcitrance cases where subjects are being too irrational. Given that recalcitrant emotions are assumed legion, this makes for widespread irrationality, which is implausible. However, we should be careful not to rule out the possibility of subjects ever being too irrational. Your fear of Fido, for instance, could be grounded in a (perhaps unconscious) judgement that Fido is dangerous, as well as being in conflict with your considered conscious judgement that Fido is harmless. Whether or not you think such cases are plausible, they remain possible, and are thereby demonstrative once again of how the two phenomena discussed by Greenspan come apart.

The fact that these phenomena come apart, as well as the fact that they overlap, is significant for the project of using rationality constraints to drive a theory of emotion. This is because it bears on how, including the extent to which, recalcitrant emotions make their bearers irrational. Having an emotion that is groundless is, prima facie, less irrational than having an emotion that conflicts with an evaluative judgement, whereas having such an emotion, in turn, is less irrational than having an emotion that is both groundless and in conflict with an evaluative judgement. Moreover, having an 
emotion that is grounded and in conflict with an evaluative judgement is more irrational than all three instances, and is what gets judgementalists in a bind.

Of course, whether these comparisons are actually true will depend on whether, and if so how, such emotions violate epistemic norms. A detailed exposition of how emotions violate epistemic norms will have to wait until we have an account of what these norms actually are, which is the topic of the next section. But assuming Greenspan's phenomena differ in the degree to which they make subjects irrational, this problematises the project of using the irrationality concerning recalcitrant emotions to inform a theory of emotion. This problem is best brought out by seeing exactly how the challenge recalcitrant emotions pose for a theory of emotion is presently understood.

As we have seen, recalcitrant emotions have gone from being used as a way of objecting to judgementalism to being independently used as a challenge for theories of emotion more generally; following Brady, this is to explain the sense in which recalcitrant emotions involve rational conflict. In this way, the challenge also extends to neo-judgementalist theories of emotion.

Neo-judgementalists take the judgementalist insight that some cognitive component, or something similarly intentional, is necessary to individuate the emotions - something traditional Jameseans, who take emotions to just consist in non-intentional feelings, struggle with. ${ }^{10}$ But they attempt to eschew the irrationality judgementalists attribute to subjects by replacing evaluative judgements with evaluative thoughts, feelings, perceptions, construals, and the like, which build in intentional contents into emotions. Fearing Fido in such instances would involve entertaining contents that are, in some sense, in tension with the contents of your judgement. You might, for instance, have negative feelings towards Fido, and ergo evaluative him negatively, despite judging that he is harmless. However, crucially, in such instances, you don't make contradicting judgements: you don't both judge that Fido is harmless and that he is harmful. Thus, though you might still be undergoing

10 Neo-judgementalists include de Sousa (1987), Helm (2001) and Roberts (2001), whereas Jamesians include James (1890/1950), Lang (1922) and Prinz (2004). 
an emotion, which is in a way inappropriate, you aren't being too irrational; you aren't contradicting yourself.

Neo-judgementalism, then, proves to be an improvement on judgementalism, as it avoids judgemental inconsistency and any resultant attributions of radical irrationality. The charge against such theories is the converse of that against judgementalism: they don't factor in enough rational conflict to account for the irrational nature of such emotions. This highlights the fact that the specific version of the challenge that recalcitrant emotions raise is often treated, e.g. by Brady and Helm, as a dilemma:

[E]ither we must be judgementalists and accept an overly strong conception of rational conflict between emotion and judgement, or we must be anti-judgementalists and give up hope of accounting for such conflict. (Helm 2001: 45)

Judgementalism is implausible on the grounds that it imputes too much irrationality to those suffering from recalcitrant emotions, whilst simple versions of neojudgementalism are implausible because they fail to impute enough irrationality to subjects of emotional recalcitrance. (Brady 2009: 414)

The dilemma characterises theories of emotion as attributing too much or not enough irrationality to those undergoing emotional recalcitrance. For instance, on the one hand judgementalists end up making subjects undergoing recalcitrant emotions 'too irrational', as these subjects are said to make self-contradicting judgements. On the other hand, anti-judgementalists don't seem to attribute any rational conflict at all, thus they fail to make sense of the phenomenon, whereas neo-judgementalists, though improving on anti-judgementalism, don't attribute enough rational conflict to account for the phenomenon.

When the challenge posed by recalcitrant emotions is understood in this way, precisely how recalcitrant emotions make subjects undergoing them irrational turns out to be crucial to settle the issue of whether a theory of emotion imparts too little or too much irrationality to subjects suffering from emotional recalcitrance. Since most of the contemporary philosophical discussion on emotion- 
al recalcitrance adheres to D'Arms and Jacobson's definition of recalcitrant emotions as involving a conflict between emotion and judgement, we can leave non-conflict involving groundless emotions discussed by Greenspan aside. But even by doing so, we are still left with the two other phenomena she discusses: conflict-involving emotions that are groundless and those that aren't. These, as we have seen, differ in the degree to which they make subjects irrational. And on account of this, whether a given theory of emotion imparts too much or too little irrationality will remain controversial and dependent on how we characterise the phenomenon. The lesson, then, is that though recalcitrant emotions are familiar, the phenomenon remains under-described, and crucially, in a way that proves significant for how a given theory of emotion is supposed to meet the challenge they pose.

This problem, though pressing, isn't too damning, as it is to an extent remediable. We can simply say more about what individual recalcitrant emotional episodes consist in, e.g. whether they are groundless, and determine whether a theory of emotions accounts for the resulting irrationality accordingly. The problem, however, highlights two concerns with the overall project. First, because 'recalcitrant emotions' pick out distinct phenomena, which differ in the extent to which they make subjects undergoing them irrational, we can't speak about the irrationality of subjects undergoing emotional recalcitrance tout court. Any assessment of whether a given theory of emotion captures the sense in which recalcitrant emotions make their bearers irrational must be assessed on a phenomenon-by-phenomenon basis, i.e. whether the cases, in addition to involving conflict, are groundless or grounded. This isn't how assessments of theories of emotion, vis-a-vis recalcitrant emotions, currently proceed.

Second, the whole endeavour of using recalcitrant emotions to drive a theory of emotion is premised on the intuition that recalcitrant emotions make their subjects irrational and the assumption that any such theory should capture this intuition. Insofar as the intuition tracks different phenomena, with differing degrees of irrationality, we see that it can't be very fine-grained in terms of the irrationality with which it imbues subjects undergoing emotional recalcitrance. The intuition, that is, doesn't speak to the precise sense in which recalcitrant bouts make their subjects irrational, 
or indeed the degree to which they do so. This makes it highly contestable whether the intuition, by itself, can act as a marker for whether a theory of emotion eschews the dilemma. Both concerns, prescribe a revision to the current methodology of using recalcitrant emotions to inform a theory of emotion. In the second instance, what we require is an articulation of the relevant epistemic norms that are violated, and a detailed account of how the two (or possibly more) phenomena tracked by 'recalcitrant emotions' violates them. Only then can we have any hope of judging the extent to which recalcitrant emotions make their bearers irrational, i.e. on account of how they violate certain epistemic norms. In the next section, we see that even doing so mightn't help settle the matter.

\section{II.}

As we have seen, articulating a theory of emotion, which captures the intuition that recalcitrant emotions make subjects undergoing them irrational because they seem to violate certain epistemic norms, is made difficult on account of these emotions themselves being under-described. The charge against such theories is that they make subjects undergoing emotional recalcitrance either too irrational or not irrational enough. Nevertheless, since 'recalcitrant emotions' picks out phenomena that come apart, and in ways relevant to how, as well as the degree to which, they make subjects irrational, we are not in a position to adequately adjudicate whether a given theory succumbs to this charge.

Even if this problem could be overcome, say by a more careful description of the cases in question, there is, however, another way in which adjudicating the matter proves difficult; one that can't be easily remedied. This concerns the normative principles which recalcitrant emotions are supposed to violate. The problem here is not that no such principle is violated, but that there are too many different principles that are plausibly violated, which in turn give differing verdicts on the irrationality shrouding recalcitrant emotions. This has the consequence, once again, of frustrating any effort to adjudicate whether a given theory attributes enough irrationality to subjects undergoing recalcitrant emotions. Nevertheless, unlike the previous problem, this is not one which can be easily 
fixed, as it will not go away until we have settled the controversy over which epistemological framework we should adopt towards the emotions more generally.

Philosophers of emotion typically don't articulate precisely which principles are violated by emotional recalcitrance. Rather, what we tend to find are appeals to the intuition that they are violated — which supposedly grounds the intuition that they make their bearers irrational — followed by expositions of how a given theory of emotion accounts for this irrationality. For instance, Brady notes that in undergoing a recalcitrant emotion "it seems as though the subject is violating some normative principle governing the relation between emotions and evaluations" (2009: 413). To be fair to Brady and other philosophers of emotions, they do hint at the types of normative principles potentially violated, even though they don't specify any instances of these types. In particular, they tend to speak of epistemic (or theoretic) rationality vs. practical rationality, but without articulating which specific epistemic or practical norms are actually violated when a subject has a recalcitrant emotion.

Brady himself speaks of "epistemic irrationality", "which goes to the heart of our intuition that they violate normative principles governing the relation between emotion and evaluations" (pg. 428). We then find an explanation of how recalcitrant emotions make their bearers irrational, and in a way that evades the too-irrational-or-non-irrational-enough charge. In brief, Brady assumes having an emotion inclines one to assent to an evaluative construal of the relevant object or situation. Moreover, he argues recalcitrant emotions make a subject irrational because they incline one to accept a construal, which one has already determined to be false. Fearing Fido is irrational, for example, because one is inclined to assent to the emotion's construal of Fido as being dangerous despite having already judged this construal to be false. This is supposed to evade the dilemma because the subject undergoing emotional recalcitrance endures some sort of rational conflict, but not one that makes her too irrational, e.g. make contradicting judgements. 
It is not my intention here to deny that Brady's explanation provides a plausible account of how recalcitrant emotions make their bearers irrational. ${ }^{11}$ The point is, such explanations are typically provided without any articulation of the relevant epistemic principles, let alone a story of how they are violated. The exception is Döring (2015) who provides two principles which might be thought to be violated when we undergo emotional recalcitrance:

(i) The Consistency Principle: "Rationality requires of you (whatever person you are) that you do not both judge that $p$ and judge that not- $p$ " (2015: 387).

(ii) The Enkratic Principle: "Rationality requires of you (whatever person you are) that, if you believe at t that you yourself ought to $\phi$, then you intend at t to $\phi "$ (2015: 389). ${ }^{12}$

The consistency principle is the epistemic normative principle which is violated if one assumes judgementalism. This is demonstrated clearly by Greenspan's objection. By contrast, the enkratic principle is a practical normative principle which is violated on the proviso that we also assume that emotions have motivational force, i.e. that they incline us to act in certain ways. As Döring explains, undergoing a recalcitrant emotion violates the enkratic principle because it motives us to act akratically. For example, if you believe that you ought to hike in the alps (say because you believe it to be safe and you would like to do so), a recalcitrant fear of heights will violate the enkratic principle insofar as it prevents you from intending to go hiking.

11 See Tappolet (2012: §1.5) for a response. Brady (2013: 112) also offers a different, sparser, explanation of the irrationality: recalcitrant bouts are irrational because nothing about the object or event constitutes adequate reason for the emotion. As I read Brady, this is supposed to augment his earlier account. Very roughly, recalcitrant episodes are irrational because they involve searching for "reasons that bear on the accuracy of our emotional construals, despite the fact that we have endorsed the opposing evaluative view in judging as we do" (2013: 177).

12 Döring also mentions and rejects two further principles, one she ascribes to Tappolet (pg. 393) and the other to Helm (pg. 396). 
Döring herself is interested in the question of whether being recalcitrant makes emotions irrational independently of their content. She grants that subjects who undergo emotional recalcitrance tend to violate the enkratic principle, but denies that this suffices to make them irrational. Crucially, following Broome (2013), she assumes that rationality consists not in corresponding correctly to reasons but rather in satisfying requirements of coherence. On this assumption, it is only the violation of the consistency principle which will make us irrational, but there is also no reason to suppose that recalcitrant emotions make us violate this principle if we forgo judgementalism. Döring's conclusion is that recalcitrant emotions don't actually make us irrational. I will have more to say about this position in the next section. For now, note that this conclusion is supported by not entirely uncontroversial assumptions about rationality. Pace Broome, if we allow rationality to involve responsiveness to reason, for instance, recalcitrant emotions will turn out to make their bearers irrational.

Döring's list also isn't exhaustive of the ways recalcitrant emotions might make us irrational. Constraints on emotional rationality have been discussed independently, e.g. by de Sousa (1987). These constraints provide some possible, and crucially distinct, ways recalcitrant emotions make those who undergo them irrational. By way of illustration, consider the following:

(iii) Cognitive rationality: a subject is rational in undergoing an emotion if that emotion is adequate to some state of the world it purports to represent.

(iv) Strategic rationality: a subject is rational in undergoing an emotion if that emotion fulfils its function.

(v) Axiological rationality: a subject is rational in undergoing an emotion if that emotion fits some paradigm scenario.

This list isn't supposed to be exhaustive either, but is illustrative of some differing constraints on rationality concerning emotion. It also has implications for how emotions can be irrational. For any 
given constrain we take to be relevant, we can suppose that having an emotion is irrational when doing so violates that constraint. Consider the following such breaches in rationality.

In terms of (iii), provided all emotions concern an evaluation of an object or situation to which they respond, having a recalcitrant emotion can make a subject irrational in that the evaluation it makes misrepresents the world. For example, fearing Fido makes one irrational because this misrepresents Fido as dangerous when he clearly isn't. We find a view akin to this in Tappolet's (2012) discussion of emotional recalcitrance. Emotions are said to have correctness conditions, e.g. we assess our emotions on the basis of how they fit the world - a feature which she takes to be indicative of the representational nature of emotion. "We criticise our fears when they are about things the are not fearsome, for instance. This practice suggest that the object of fear is represented as fearsome" (Tappolet 2012: 210). A similar point is made by Brady (2013) himself:

$[1] \mathrm{t}$ is irrational to be ashamed of things that one does not judge to be shameful, or to feel guilt when one believes that one has done nothing wrong. And it is irrational to be ashamed or guilty in these circumstances because nothing about the object or event constitutes a good enough reason for shame or guilt” (Brady 2013: 112).

Like (iii), the above rationality constraint involves a mind-to-world direction of fit. That is, the emotion, particularly the evaluation it makes, aims to fit the world. What the quote nicely brings out is that, contra (iii), we needn't make any presuppositions about representation to make this point. The emotion can be said to not fit the world because the object or event that elicits the emotional response doesn't provide sufficient reason for this response. ${ }^{13}$ In either case, the emotion can be thought ill-fitting, and thus their subjects irrational.

Quite independent of this, according to (iv), an emotion can make its bearer irrational if it inhibits its function. What this function exactly is, of course, will be controversial. For de Sousa, the

13 This account of emotions involving justificatory reasons is discussed in more detail in Brady (2007). 
function of emotion, broadly speaking, is to guide us in reasoning. But more specifically, the biological function of emotion is to do something reason can't, viz. to determine the salience of features of perception and reasoning. It is this idea is which is expressed by evolutionary psychologists Ketelaar and Todd (2001) when they claim that "specific emotions might help to solve the problem of what information to attend to in specific environmental circumstances” (pg. 194).

To elaborate, in any given instance, there is an infinite amount of information we could pay attention to, and we cannot ipso facto determine, simply by reasoning, which are actually worthy of consideration. Emotions streamline this process by making certain features salient, and thereby worthy of our consideration. ${ }^{14}$ On this account, having an emotion is irrational when doing so inhibits this function, say by making us pay attention to features of the environment that aren't significant. For instance, the function of fear is to draw attention to features of our environment that may prove dangerous. The recalcitrant bout of fearing Fido thereby makes a subject irrational because she ends up paying too much attention to Fido, who is already known to be harmless. ${ }^{15}$

Independent of these considerations, with regards to (v), an emotion can also be thought to make their bearer irrational if it doesn't fit any relevant paradigm scenarios. Paradigm scenarios are "the historic origins of an individual's experience of and capacity for the emotions involved" (de Sousa 1987: 50). These are a product of both our biology and culture, and consist of the following two aspects:

[F]irst, a paradigm situation providing the characteristic objects of the emotion (where objects can be of various sorts, sometimes more suitably labelled "target," or "occasion") and second, a set of characteristic or "normal" responses to the situation. (de Sousa 1987: 55)

\footnotetext{
${ }^{14}$ Damasio's (1994) Somatic-Marker Hypothesis proposes a similar thesis. Very roughly, somatic states, i.e. feelings about the body that are associated with past experiences, assist deliberation by highlighting some options as either favourable or unfavourable.

15 Another form of strategic irrationality is due to Döring, who explains the intuition that recalcitrant emotions make us irrational on grounds that they interfere with "the reasoned pursuit of our goals" (2014: 128).
} 
The difference between cognitive and axiological rationality is that an emotion is rational according to the former if it fits the world (or some feature of the world it purports to represent), whereas it is rational according to the latter if it fits some paradigm scenario, roughly a stereotypical situation that acts as a guide for the kinds of situations which are appropriate for emotional responses of this type. With regards to the axiological framework, then, an emotion can be said to make one irrational if it occurs in a way that doesn't fit the relevant paradigm scenario. This can happen when the emotional response is a reaction to an object that isn't characteristic of objects that elicit emotional responses of this type, e.g. fearing a harmless docile dog such as Fido, as opposed to some vicious canine exposing its teeth and barking aggressively. It can also happen when an emotional response exceeds the normal set of responses to a situation. Feeling slightly alarmed, even fearful, at being surprised by a dog that walks into a room would (presumably) constitute a normal response, but feeling abject fear, and remaining to do so wouldn't. Such a response would, hence, make one irrational.

From de Sousa's list of ways emotions can be thought to make their bearers irrational, only (iii) has a bearing on the irrationality shrouding recalcitrant emotions directly in terms of a conflict between emotion and evaluative judgement. (In brief, both the emotion and the judgement purport to represent the world, but they come to have conflicting representational contents). But all three might speak to the intuition that recalcitrant emotions make their bearers irrational because they violate certain epistemic norms. For instance, as we saw with the axiological rationality constraint, we can say that fearing Fido is irrational because it doesn't fit any relevant paradigm scenarios. Likewise, via the strategic rationality constraint, we can say that fearing Fido is irrational because this doesn't fit the biological function of fear. It is prima facie plausible that a violation of either of these constraints can help explain the sense in which fearing Fido is thought irrational. If this is right, crucially, it means that there needn't be any rational conflict between emotion and judgement to account for the said intuition. We can explain it by other means. 
Now given that only the cognitive rationality constraint speaks to how recalcitrant emotions result in a rational conflict, mightn't it be that only this constraint really accounts for our intuitions about the irrationality concerning recalcitrant emotions? 16 This, I take it, is plausible. However, intuitions aren't the sorts of things which are very fine-grained. Since a violation of the other constraints, including Döring's normative principles, also account for how recalcitrant emotions are irrational, there is no guarantee that our intuitions about the irrationality of recalcitrant emotions, including our intuitions about the degree to which they are irrational, aren't influenced by a violation of these constraints. It therefore remains plausible also that all five constraints are relevant when it comes to accounting for our intuitions.

An added complication concerns the perspective from which we are supposed to assign attributions of irrationality. Attributions of irrationality that concern breaches in (i)-(v), for instance, are made from a subject-independent perspective, but attributions of irrationality might also be made from the subject's perspective. This needs some exposition. The conflict manifest in recalcitrant emotions concerns not a tension between the evaluative component of an emotion and the way the world is. Rather, it concerns a tension between the evaluative component of an emotion and the way the subject takes the world to be, i.e. her evaluative judgement. This lets us attribute some level of irrationality to the subject, for her representation of the world contains two conflicting representational contents. Moreover, we can make such attributions from a subject-independent perspective. That is, we can describe the subject as being irrational whether she thinks she is or not.

Nevertheless, some explanations of the irrationality concerning recalcitrant emotions centre not on the irrationality we may attribute to the subject, but on the irrationality which the subject attributes to herself. In providing an explanation that very much resembles the above explanation of breaches in the principle of rationality concerning (iv), Brady argues that mobilisation of our fightor-flight responses when we have already judged something to be harmless is "at least from S's perspective, a waste of her limited motivational resources: it is akin to S's preparing for a race that she

\footnotetext{
16 I am grateful to an anonymous referee for this suggestion.
} 
sees no need to run" (2009: 427). The same is true of the mobilisation of her cognitive resources, e.g. attending to the stimuli the subject judges to be harmless: "From S's perspective, such focussed attention and increased sensitivity is a pointless waste of limited cognitive resources" (2009: 427).

This opens up even more possibilities with regards to the ways in which recalcitrant emotions can make those who undergo them irrational, and for there to be conflict in such attributions. For example, if a subject falsely judges a lion he sees on safari to be tamed and thereby harmless, his fear response towards the lion won't be irrational in terms of say (iv). His response is fulfilling its biological function as it should. Yet, the subject might still take himself to be irrational, as he feels fear despite judgements to the contrary. This once again problematises any effort to judge whether a given theory of emotion attributes enough irrationality to the subject undergoing this bout of recalcitrant fear.

The situation, of course, is made worse by the fact that all five of the aforementioned ways emotions can be thought to make their bearers irrational can also be thought to make them irrational from the subject's perspective. Thus, there are at least ten distinct conflicting ways recalcitrant emotions can be thought to concern irrationality: the actual violations in constraints (i)-(v), and the supposed violations of these constraints from the subject's perspective. The upshot of this is that, as in section $\S$ I, whether a given theory of emotion attributes enough irrationality to subjects undergoing emotional recalcitrance will be controversial. But there are two differences. First, in this instance, the controversy results not because of the way we characterise the phenomenon, but because of the epistemic principles that may be violated. Second, this controversy is not easily remedied because which principles are actually relevant for the rationality of emotions more generally is presently controversial. Which of the constraints (i)-(v) are actually relevant for emotional rationality? All of them? Some of them? None of them? The philosophy of emotions is nowhere near to answering these questions. Nevertheless, until we settle this issue of which epistemological framework we ought to adopt with regards to the emotions more generally, we cannot settle the controversy over how irrational having recalcitrant emotions really are. All of this suggests that the present practice of using 
the intuition that recalcitrant emotions are irrational to inform a theory of emotion is, and will likely remain, deeply problematic.

III.

To recap, recalcitrant emotions are said to raise a challenge for a theory of emotion, viz. to explain the precise sense in which subjects undergoing these emotional episodes are being irrational. This paper aimed to raise scepticism with the endeavour of using this challenge to drive a theory of emotion. The arguments provided did not require us to deny the intuition that acts as the basis for this challenge: the intuition that subjects possessing recalcitrant emotions are being irrational, as these emotions seem to violate certain epistemic norms. Instead, it was demonstrated that the irrationality shrouding recalcitrant emotions - whether they make their bearers irrational, how they do so, and the degree of irrationality concerned - is extremely controversial.

The controversy results from two factors. First, the phenomenon of emotional recalcitrance is under-described, and it is not clear whether all instances emotional recalcitrance track the same phenomenon. Second, they are too many distinct epistemic norms that may be violated by these phenomena, ones which give differing, and often conflicting, verdicts on the irrationality of those who undergo them. Crucially, the second factor, as we saw, isn't easily remedied. This matters because it means adjudicating whether a given theory of emotion meets the challenge can't be settled in an unproblematic way, as the precise nature of the challenge in itself is, and will likely remain, controversial.

There are two ways a philosophy of emotion might proceed in the face of such scepticism. The first is to resist it. Though the content of this paper has been overwhelming negative, it also sheds some light in how we might overcome such scepticism. As evident, we need to be a lot clearer about both the phenomenon of interest and the epistemic norms that are (supposedly) violated when this phenomenon occurs. In terms of the former, not all irrational emotions need be recalcitrant. Moreover, even ones that are, as we saw, can differ in the ways they affect how, as well as the 
degree to which, they make their bearers irrational. One option is to double-down on a more specific definition of emotional recalcitrance. A better option is to provide an exposition of the varying phenomena caught under the broader umbrella of 'emotional recalcitrance', and make our assessments of irrationality by taking these differences into consideration. For example, in Greenspan's (1981) original example, the subject fears all dogs, including Fido, because they've been traumatised on account of being bitten by a rabid dog previously. In this case, the subject presumably has some form of post-traumatic stress disorder, which is quite reasonable, or at least far more reasonable than simply fearing a dog they judge to be harmless. Therefore, it helps to make a distinction between recalcitrant emotions which are groundless and those that aren't, and make assessments about their irrationality accordingly.

The problem of filling in the specificities of the recalcitrant cases we choose to consider doesn't seem insurmountable. What proves more difficult is agreeing on a set of norms by which to judge whether the recalcitrant cases we consider actually involve any norm violations. As we have seen, the difficulty is owing to an abundance of distinct epistemic norms which might violated when we undergo emotional recalcitrance. This difficulty is compounded by two factors. First, which epistemic norms apply to recalcitrant emotions will (partly) depend on which norms apply to emotions more generally. Second, which epistemic norms apply to emotions more generally will, in turn, (partly) depend on which epistemic norms govern human rationality. The worry, then, is that until we have settled these issues, we cannot make any real progress in determining whether, and if so how, recalcitrant emotions make their bearers irrational.

I don’t think we should down play these worries. Nevertheless, there is still room to make some progress. Not all norms concerning human rationality will bear on emotion. Moreover, even ones that do might not be specific to emotional recalcitrance. Subsequently, if we are to explain what's so irrational about recalcitrant emotions in particular, we could begin by looking at norm violations that are specific to emotional recalcitrance. The consistency principle is a good candidate. If judgementalism is true, by having a recalcitrant emotion you violate this principle, i.e. you both 
judge that $p$ and not- $p$. Moreover, this isn't a norm which is violated when you undergo other kinds of irrational emotions, e.g. where you have a groundless emotion that doesn't involve any conflict between emotion and judgement.

The problem with the consistency principle, of course, is that it isn't violated unless we assume judgementalism. So if we are to insist that recalcitrant emotions involve a rational conflict between emotion and judgement, and that a theory of emotion should explain this, we also need an epistemic norm that is plausibly violated even if we forgo judgementalism. Something along these lines is suggested Brady himself. According to Brady, "it seems plausible to suppose that someone suffering from recalcitrant emotions is subject to a certain rational requirement, namely to ensure that her emotions and her evaluative beliefs line-up" (2007: 276). Brady doesn't think this suffices to explain how recalcitrant emotions make their bearers irrational. But it does motivate a different kind of consistency principle, one which is also violated when we undergo emotional recalcitrance:

(vi) Consistency principle*: rationality requires of you (whatever person you are) that whenever you have an emotion that conflicts with a judgement, you out to either revise your emotion or your judgement.

I think this is a step in the right direction. Unlike the consistency principle considered earlier, this principle has the benefit of being the kind of principle which is violated whether or not one assumes judgementalism. However, I also think the applicability of this principle is hostage to two factors, both of which are controversial.

First, there must be some reason why rationality should require of us that we either revise our emotions or our judgements when we undergo emotional recalcitrance, as not all conflicting mental states seem to require such revision. For example, rationality doesn't seem to require of you that you change your perception or judgement when they are in conflict. Here Döring provides an answer. Emotions have motivational force; they incline us to act in certain ways, even ones that con- 
flict with our goals. Subsequently, there is good reason to try to change our emotions when they interfere with the reasoned pursuit of our goals. For example, if being unjustifiably jealous makes you behave in a way that threatens your relationship, there is good grounds for you to try to stop being so jealous. There are other reasons too. Some, but by no means all, recalcitrant emotions, make their bearers suffer. Feeling immensely jealous can be agonising, ergo a subject who agonises in this way has good cause to alter their emotional state - ie. whether or not this also influences their behaviour.

Second, emotions should also be the kinds of things that can undergo revision. Following Tappolet (2012, 2017), I'm assuming here an 'ought implies can' principle. To elaborate, recalcitrant emotions often involve a conflict between an emotion and a considered evaluative judgement. If emotions aren't malleable, applying the consistency principle* means that we should always revise our judgements, even our considered ones. This proves problematic as it brings us in tension with other considerations of rationality. It would be odd, for instance, to insist that you should change your judgement when you undergo a recalcitrant bought of jealousy, especially if you know that your partner loves you and is highly unlikely to stray. By contrast, following Tappolet, emotions, I take it, exhibit some form of plasticity. In particular, we can influence our emotional dispositions over time. ${ }^{17}$ So while we cannot revise a bout of recalcitrant jealousy in that very moment, we can change our dispositions for jealousy in a way that there can be some requirement of us that we should, at least sometimes, revise our recalcitrant bouts of jealousy, as opposed to our considered judgements.

I take these considerations to be plausible but also speculative. The point here isn't to really side with a particular response to the challenge of recalcitrant emotions, let alone offer a new one, but to highlight how we might plausibly make progress in terms of articulating the kinds of constraints that would enable us to to employ the irrationality concerning emotional recalcitrance as a general benchmark for a theory of emotion. As evident, we can make some progress in terms of ar-

\footnotetext{
17 Also see Faucher and Tappolet (2007, 2008), and Majeed (2019).
} 
ticulating the constraints that apply specifically to emotional recalcitrance. Nevertheless, as also evident, any progress we can make will itself be subject to other considerations, e.g. considerations about the nature of emotions, as well as more general considerations about the nature of human rationality. Considerations, which at present, remain controversial.

All of this can also be seen to motivate a more radical response, namely instead of resisting the scepticism raised in this paper we can just embrace it. The contemporary challenge of emotional recalcitrance is understood to be one where it is a condition of adequacy for a theory of emotion that we should be able to employ it to explain the sense in which such recalcitrant emotional episodes involve rational conflict. As we have seen, not only are our current attempts to employ this condition problematic, but there are serious obstacles to making any progress in terms of applying this condition in a problem-free manner. This provides grounds to drop the adequacy constraint. That is, we adopt a sort of quietism about emotional recalcitrance, one where we no longer suppose that there is any general challenge posed by such emotions.

An upshot of this sort of quietism is that versions of neo-judgementalism, which were criticised by Brady (2009) for not attributing enough irrationality to those undergoing emotional recalcitrance, should now be put back on the table. To clarify, this needn't entail that we put judgementalism itself back on the table. We can suppose that judgementalism is problematic because of what it suggests about recalcitrance cases, but we can simultaneously forgo the need to generalise, i.e. employ recalcitrant emotions as a measure of any given theory of emotion. If we are to go this route, we need some story about why the irrationality shrouding recalcitrant emotions is relevant as a condition of adequacy for judgementalism but not for theories of emotion more generally. The content of this paper helps provide such a story.

One of the difficulties with employing recalcitrant emotions as a benchmark for a theory of emotion is that the normative constraints that might be violated by them are numerous, which result in competing accounts of why recalcitrant emotions make their bearers irrational. These normative constraints are germane for judgementalism as well. However, there is a crucial difference. There is 
one rationality constraint - arguably the most central of all — which is violated if one assumes judgementalism but that isn't on other theories of emotion, viz. the consistency principle. Judgementalism, as we saw, entails that a subject both judges that Fido is dangerous and not dangerous when they undergo a recalcitrant bout of fearing Fido. This principle isn't violated by other theories of emotion, at least not the ones presently under consideration. Embracing quietism, then, needn't be a point in favour of judgementalism.

The problem with quietism is that it will require a lot more justification. To elaborate, quietism tends to be of ill repute due to its supposed passivity in the face of substantive philosophical problems. But this rests on a misunderstanding. Speaking specifically about Wittgenstein's version of quietism, McDowell notes that "Wittgenstein's quietism is not a refusal to engage in substantive philosophy in the face of what everyone has to accept as genuine problems. It is an activity of diagnosing, so as to explain away, some appearances that we are confronted with genuine problems" (2009: 371). The scepticism raised in this paper about the contemporary challenge of emotional recalcitrance provides a solid foundation from which to argue for a quietist position of this sort. Nonetheless, I have not argued that the problems we face are irremediable. If they can be overcome, quietism would prove premature.

Here it would be remiss not to mention Döring's response to the contemporary problem of emotional recalcitrance, which like quietism also raises scepticism about the contemporary challenge of emotional recalcitrance. Though the two positions are slightly different. While the form of quietism mentioned above is motivated by a lack of a clear epistemic framework to ensure that our intuitions about the irrationality surrounding recalcitrant emotions are correct, Döring strikes a stronger verdict: our intuitions are wrong-headed as subjects undergoing recalcitrant emotions aren't actually irrational. If she right, her view can be used to justify our quietist position in a way that we haven't been able to thus far. As we saw earlier, Döring argues for her verdict by articulating precisely the kinds of normative principles which I argued are missing in most discussions of the emotional recalcitrance. However, as we also saw, there are more constraints on rationality that are prima facie relev- 
ant to assessing the irrationality concerning recalcitrant emotions than Döring considers. So we can't be sure whether her position is ultimately warranted until we take stand on these other constraints.

As I see it, whether we adopt the first or second option will, ultimately, depend on how much progress we can make towards specifying the normative principles actually violated when we undergo emotional recalcitrance. Nothing I have said in this paper suggests that this would be impossible. By the same token, all evidence suggests that it will require considerable work. I won't make a guess as to the outcomes of such an endeavour here. Instead, let me end by reiterating what I take to be the central lesson of this paper: make of recalcitrant emotions what you will, but as things stand, it is ill-advised to employ the intuition that subjects undergoing emotional recalcitrance are being irrational to inform a theory of emotion.

\section{REFERENGES}

Benbaji, H. (2013). "How is Recalcitrant Emotion Possible?" Australasian fournal of Philosophy: 1-23. Brady, M. S. (2007). 'Recalcitrant Emotions and Visual Illusions'. American Philosophical Quarterly 44 (3):273 - 284 .

— (2009). 'The Irrationality of Recalcitrant Emotions'. Philosophical Studies 145: 413-30.

- (2013). Emotional Insight: The Epistemic Role of Emotional Experience. Oxford: Oxford University Press.

Broome, J. (2013) Rationality Through Reasoning. Malden, MA: Blackwell.

Damasio, A. R. (1994). Descartes' Error: Emotion, Rationality and the Human Brain. New York: Putnam

D’Arms, J., \& Jacobson, D. (2003). 'The Significance of Recalcitrant Emotion'. In Philosophy and the Emotions, edited by A. Hatzimoysis. Cambridge: Cambridge University Press, 127-145. 
Deonna, J. A., and Teroni, F. (2012). The Emotions: A Philosophical Introduction. London and New York: Routledge.

de Sousa, R. B. (1987). The Rationality of Emotion. Cambridge and London: MIT Press.

Dillon, R. S. (1997). 'Self-Respect: Moral, Emotional, Political'. Ethics 107 (2): 226-249.

Döring, S. A. (2014). 'Why Recalcitrant Emotions Are Not Irrational'. In Emotion and Value, edited by

R. Roeser and C. Todd. Oxford: Oxford University Press, 124-136.

— (2015). 'What's Wrong With Recalcitrant Emotions?' Dialectica 69(3): 381-402.

Faucher and Tappolet (2007). Facts and Values in Emotional Plasticity. In Fact and Value in Emotion;

Consciousness and Emotion Book Series, edited by L. Charland \& P. Zachar. John Benjamins, 101-137.

— (2008). The Modularity of Emotions. Alberta: University of Calgary Press.

Greenspan, P. S. (1981). 'Emotions as Evaluations'. Pacific Philosophical Quarterly 62: 158-69.

- (1988). Emotions and Reasons. London: Routledge.

Griffiths, P. E. (1997). What Emotions Really Are. Chicago and London: Chicago University Press.

Grzankowski, A. (2016). 'The Real Trouble with Recalcitrant Emotions'. Erkenntnis 82(3): 641-651.

Helm, B. (2001). Emotional Reason. Cambridge: Cambridge University Press.

James, W. (1890/1950). The Principles of Psychology. New York: Dover.

Lang, G. G. (1922). The Emotions, translated by I. A. Haupt. Baltimore, MD: Williams and Wilkins.

LeDoux, J. E. (1996). The Emotional Brain: The Mysterious Underpinnings of Emotional Life. New York: Simon \& Schuster.

McDowell, J (2009). 'Wittgensteinian “quietism”'. Common Knowledge 15 (3):365-372.

Majeed, R (2019, Online). 'Does Modularity Undermine the Pro-Emotion Consensus?' Mind and Language.

Nussbaum, M. (2001). Upheavals of Thought: The Intelligence of Emotions. Cambridge: Cambridge University Press.

Prinz, J. J. (2004). Gut Reactions: A Perceptual Theory of the Emotions. New York: Oxford University Press. 
Roberts, R. (2003). Emotions: An essay in aid of moral psychology. Cambridge: Cambridge University Press.

Rorty, A. O. (1978). 'Explaining Emotions'. Journal of Philosophy 75: 139-161.

Solomon, R. (1980). "Emotions and Choice". In Explaining Emotions, edited by A. Rorty. Los Angeles: University of California Press, 251-81.

Tappolet, C. (2012). 'Emotions, Perceptions, and Emotional Illusions'. In Perceptual Illusions. Philosophical and Psychological Essays, edited by C. Clotilde. Basingstoke and New York: Palgrave-Macmillan, 207-24.

— (2017). Emotions, Values, and Agency. Oxford and New York: Oxford University Press.

Weiskrantz, L. (1986). Blindsight: A Case Study and Implications. Oxford and New York: Oxford University Press. 